\title{
Molecular Study of a Phytoplasma Associated with Safflower Fasciation in Iran
}

\author{
H. MAHMOUDI ${ }^{1}$, M. SALARI ${ }^{1}$, M. GHAYEB ZAMHARIR ${ }^{2} *$ and M. GHORBANI ${ }^{3}$ \\ ${ }^{1}$ Department of Plant Protection, Faculty of Agriculture, University of Zabol, Zabol, Iran \\ ${ }^{2}$ Plant Diseases Research Department, Iranian Research Institute of Plant protection, Agricultural Research, \\ Education and Extension Organization (AREEO), Tehran, Iran \\ ${ }^{3}$ Department of Biology, Faculty of Science, University of Birjand, Birjand, Iran
}

(Received: 13 April 2019; accepted: 9 July 2019)

\begin{abstract}
A safflower disease was observed in the fields of South Khorasan (Iran) in 2017-2018. Affected plants had extensive fasciation, bushy growth, small leaves, phyllody and shortened internodes. Polymerase chain reaction (PCR) assays were performed using universal phytoplasma primers pairs P1/P7, R16mF1/mR1 and M1/ M2 to detect putative phytoplasma (s). Nested PCR analyses showed that all symptomatic plants were positive for phytoplasma infection, while asymptomatic plants were negative. Nucleotide sequence analysis and RFLP analyses of PCR-amplified 16S rDNA sequences indicated that safflower fasciation in Iran was associated with a phytoplasma that belonged to the peanut witches' broom group (16SrII). Phylogenetic analysis confirmed that safflowers fasciation phytoplasma (SaP) must be classified in 'Candidatus phytoplasma aurantifolia' (16SrII) taxonomic group. To our knowledge, this is the first documentation of a phytoplasma associated with safflower fasciation in Iran and the world.
\end{abstract}

Keywords: 'Candidatus phytoplasma aurantifolia', fasciation, safflower.

Safflower (Carthamus tinctorius) is one of the oldest crops that was commercially cultivated for seed oil (Zohary et al., 2012). Safflower is infested with several fungal, bacteria and phytoplasma, causing serious diseases.

Over the recent years, a phytoplasma-like disease has been observed in several safflower fields in South Khorasan (Iran). Symptoms included extensive fasciation, formation of bushy growth, phyllody and shortened of internodes (Fig. 1). The rate of incidence of symptomatic safflower are $<0.2 \%$ per field. Symptoms are typical of those diseases caused by phytoplasmas therefore studying the disease etiology is necessary.

Phytoplasmas are obligate bacterial parasites of plant phloem tissue (Lee et al., 2000; Hogenhout et al., 2008) that are transmitted by insects (Lee et al., 2000; Weintraub and Beanland, 2006). Phytoplasma taxonomy is complicated because the organisms cannot be cultured; methods normally used to classify prokaryotes are thus not available (Lee et al., 2000). Phytoplasma taxonomic groups are classified based on differences in fragment sizes produced by restriction digests of $16 \mathrm{~S}$ ribosomal RNA gene sequences (RFLPs) or by comparisons of DNA sequences from 16s/23s spacer regions (Hodgetts et al., 2007). 
Phytoplasmas are pathogens of agricultural plants including safflower. The major phytoplasma disease in this plant is phyllody that has been reported for the first time from Israel (Klein, 1970), followed by Iran in 2008 (Salehi et al., 2009). To our best knowledge, the symptoms described in this article are new for Iran and the world. The objective of this study was to determine the causal agent of the symptoms observed in safflowers field in South Khorasan (Iran).

\section{Materials and Methods}

\section{Plant samples and DNA extraction}

Leaf tissues were sampled from a total of 12 symptomatic safflower plants from two locations in Amirabad region (Birjand, South Khorasan, Iran) in 2017 and 2018. In addition, seven asymptomatic plants were sampled from these fields to be used as healthy plants. Total DNA was extracted from $0.5 \mathrm{~g}$ of leaf tissue of each safflower plants using CTAB-based method (Doyle and Doyle, 1987).

\section{Triplet nested PCR}

The PCR conditions were as follows:

A triplet nested PCR assay using primer pair P1/P7 (Deng and Hiruki, 1991; Schneider et al., 1995) in the first amplification followed by R16mF2/R16mR1 (Gundersen and Lee, 1996) in the second amplification and M1/M2 (Gibb et al., 1995) in the third amplification was performed to detect phytoplasmas in the safflower samples. For PCR amplification, 35 cycles were conducted in an automated thermal cycler (BioRad, MyCycler ${ }^{\mathrm{TM}}$ Thermal Cycler System) with Taq polymerase (CinaGene, Karadj, Iran). Mexican lime witches broom infected sample was used as a positive control. PCR was carried out in $20-\mu 1$ reaction mixtures containing $1 \mu 1$ of undiluted nucleic acid preparation (150 ng), $200 \mu \mathrm{M}$ of each dNTP, and $0.4 \mu \mathrm{M}$ of each primer. The temperature condition was as follows: denaturation at $94{ }^{\circ} \mathrm{C}$ for $2 \mathrm{~min}(5 \mathrm{~min}$ for the first cycle to activate Taq polymerase), annealing for $2 \mathrm{~min}$ at $58{ }^{\circ} \mathrm{C}, 56{ }^{\circ} \mathrm{C}$ and $50{ }^{\circ} \mathrm{C}$, respectively, for $\mathrm{P} 1 /$ $\mathrm{P} 7, \mathrm{R} 16 \mathrm{mF} 2 / \mathrm{R} 16 \mathrm{mR} 1$ and M1/M2 primer extension for $3 \mathrm{~min}$ (5 $\mathrm{min}$ in the final cycle) at $72{ }^{\circ} \mathrm{C}$. The P1/P7 PCR yielded an amplicon that included near full-length $16 \mathrm{~S}$ rDNA (about $1.8 \mathrm{~kb}$ ). One microliter of diluted (1:30) PCR product from the first nested PCR was used as the template in the reaction mixtures $(25 \mu \mathrm{l})$ for nested PCR using R16mF2/ R16mR1. For triple nested amplification with M1/M2 primer pair, nested PCR products diluted with sterile distilled water (1:30). Phytoplasma positive controls employed for the molecular analyses included almond witches broom phytoplasma (AWBP, 16SrIX-B, 'Ca. P. phoenicium'). Samples devoid of DNA template were added as negative controls for the PCR and nested PCR reactions. The PCR products $(6 \mu \mathrm{l})$ were electrophoresed through a $1.2 \%$ agarose gel, stained in ethidium bromide, and visualized with a UV transilluminator. 


\section{Phylogenetic analysis and in silico RFLP}

The obtained sequences were assembled, aligned and compared with nucleotide sequences in the GeneBank database, using BLAST (version BLASTN 2.2.18) (NCBI, Bethesda, MD, USA) and deposited in GenBank as accession numbers MK484137, MK484138 and MK484139. Sequence alignments were performed by using ClustalX (Thompson et al., 1997). Phylogenetic analyses were done by maximum parsimony (MP) analysis using the close-neighbour-interchange algorithm, 16S rDNA sequence from safflower samples 129, 130, 135 and from 45 'Candidatus phytoplasma' strains by Acholeplasma laidlawii as the outgroup. The analysis was replicated 1000 times. A bootstrap analysis was performed to estimate the stability and support for the inferred clades (Tamura et al., 2004).

In silico RFLP analysis was performed for the partial sequences of $16 \mathrm{~S}$ rDNA samples $129,130,135$ bounded by the two conserved nucleotide blocks corresponding to the annealing sites for the phytoplasma universal 16S rRNA primer pair R16F2n/R16R2 (Gundersen and Lee, 1996) and computer-simulated virtual RFLP patterns were generated by using an iPhyClassifier (Zhao et al., 2009). Each 16 S rDNA fragment was digested in silico with 17 distinct restriction enzymes (AluI, BamHI, BfaI, BstUI, DraI, EcoRI, HaeIII, HhaI, HinfI, HpaI, HpaII, KpnI, Sau3AI, MseI, RsaI, TspI and TaqI) that were used for the phytoplasma 16S rDNA RFLP analysis (Wei et al., 2007). The virtual RFLP patterns produced by strains derived from safflower samples were compared with representatives of subgroups within 16SrII groups using a Perl program developed by Wei et al. (2008).

\section{Results}

Safflower fasciation exhibited extensive fasciation, formation of bushy growth, small leaves, phyllody and elongation of internodes (Fig. 1). Phytoplasmas were detected in symptomatic safflower plants that were sampled from two safflower fields in South Khorasan (Iran). All 12 samples that were collected in 2017-2018 from safflower fields

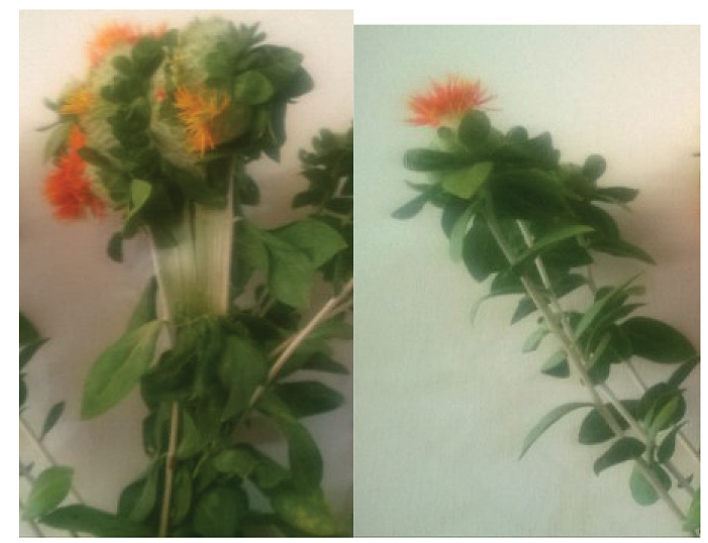

Fig. 1. Safflower fasciation symptoms (left) compared with healthy ones (right) 


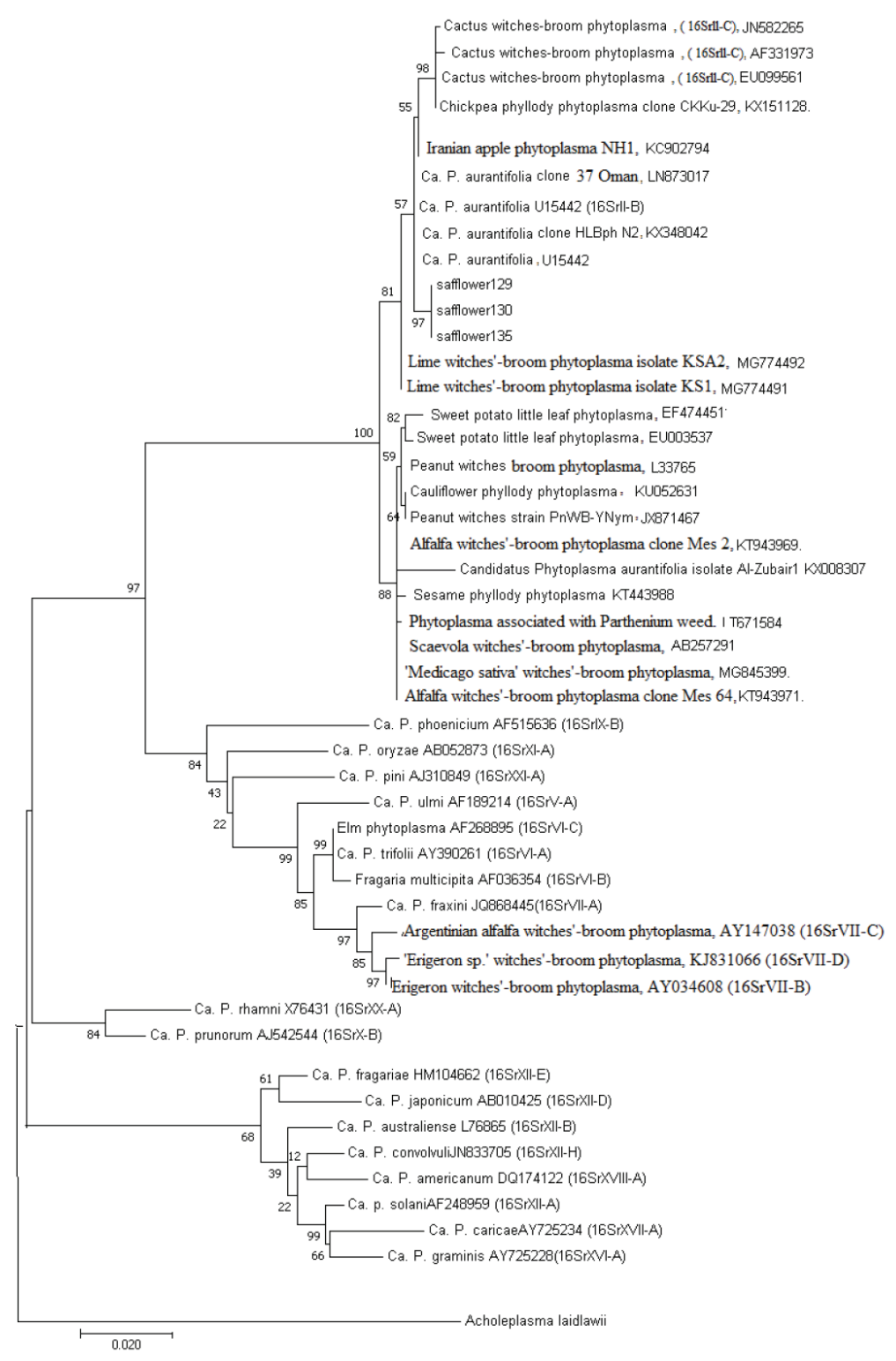

Fig. 2. Molecular Phylogenetic analysis by Maximum Likelihood method. The evolutionary history was inferred by using the Maximum Likelihood method based on the Tamura-Nei model (Tamura and Nei, 1993). The tree with the highest log likelihood (-5016.97) is shown. The percentage of trees in which the associated taxa clustered together is shown next to the branches. Initial tree(s) for the heuristic search were obtained automatically by applying Neighbor-Join and BioNJ algorithms to a matrix of pairwise distances estimated using the Maximum Composite Likelihood (MCL) approach, and then selecting the topology with superior log likelihood value. The tree is drawn to scale, with branch lengths measured in the number of substitutions per site. The analysis involved 50 nucleotide sequences. Codon positions included were $1 \mathrm{st}+2 \mathrm{nd}+3 \mathrm{rd}+$ Noncoding. All positions containing gaps and missing data were eliminated. There were a total of 1055 positions in the final dataset. Evolutionary analyses were conducted in MEGA7 (Kumar et al., 2016) 
were positive for phytoplasma infection based on the nested PCR assays. Symptomless samples tested negative for the phytoplasmas infection.

Nucleotide sequence analysis of $16 \mathrm{~S}$ rDNAs from several samples confirmed that the peanut witches broom related strain (group 16SrII) in the diseased safflower plants was very closely related to an 'Candidatus phytoplasma aurantifolia' related strain (GenBank accession no KX348042) that causes HLB disease and shared more than $99 \%$ sequence homology.

Phylogenic analysis indicated that safflower fasciation clustered inside the II group branch, the three Sf phytoplasma strains identified in this study were clustered along with the previously characterized Iranian ' $\mathrm{Ca}$. P. aurantifolia' in the different phylogenetic subclades (Fig. 2).

The results of in silico RFLP analyses of 16S rDNA sequences with five enzymes (AluI, MseI, RsaI, HaeIII and Taq I) revealed that all phytoplasma-positive samples were infected by phytoplasma strains that belonged to the peanut witches' broom phytoplasma group subgroup B (16SrII-B) as indicated by RFLP profiles that were very similar or identical to those of two 16SrII-B reference strains (Mexican Lime witches broom phytoplasma) (accession number U15442) (Fig. 3).

\section{Discussion}

The results of this study revealed that 'Candidatus phytoplasma aurantifolia'-related strain was detected in the safflower samples which showed symptoms of fasciation. The infested plants exhibited extensive fasciation. There have been several reports of phytoplasmas associated with safflower phyllody symptom in Iran (Salehi et al., 2009);
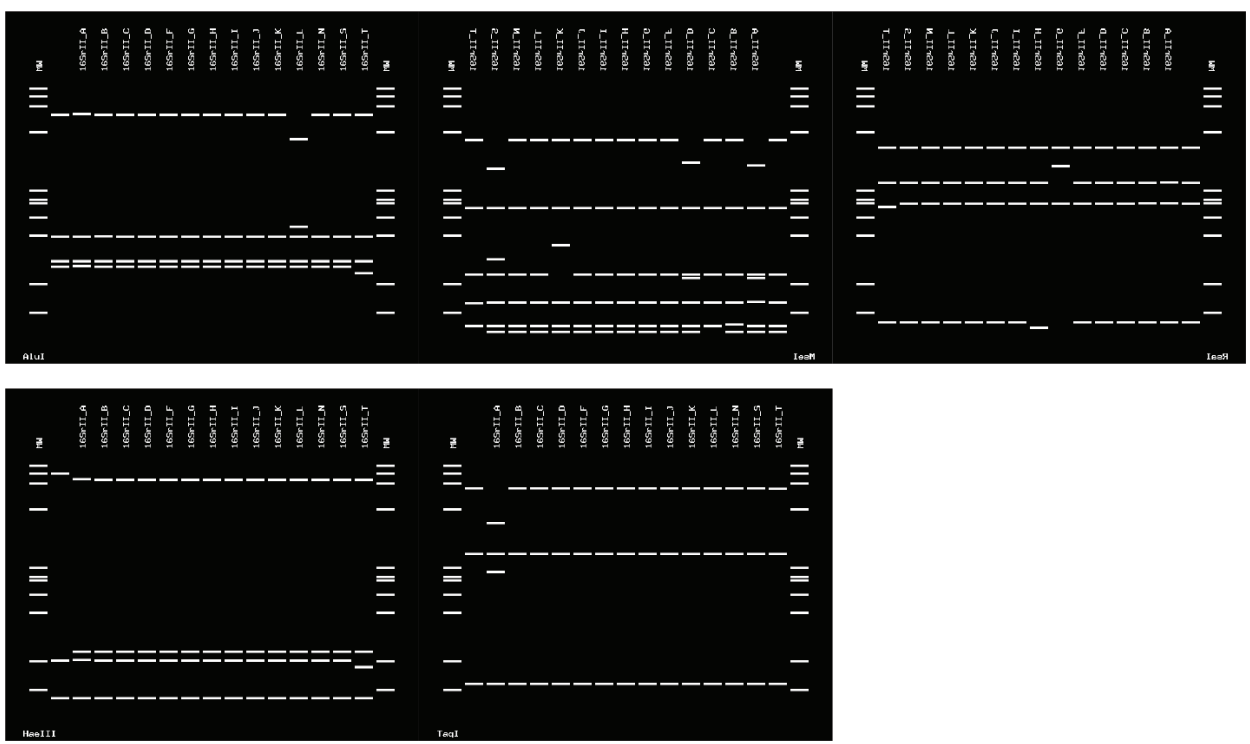

Fig. 3. Virtual RFLP patterns derived from in silico digestions of $16 \mathrm{~S}$ rDNA (1.25 kbp fragments) from the safflower fasciation phytoplasma and reference isolates of II group using key restriction endonuclease enzymes: RsaI, MseI, AluI, HaeIII and TaqI. MW is $\Phi \mathrm{X} 174$ DNA digest by HaeIII 
however, this is the first report of natural infection of safflower by a phytoplasma that was related to peanut witches' broom group subgroup B (16SrII-B), showing fasciation.

The most economically important disease caused by 'Candidatus phytoplasma aurantifolia' has been Mexican lime witches broom, which is widespread in southern Iran and causes severe loss in the Mexican lime industry (Zreik et al., 1995).

The host plant range of peanut witches' broom phytoplasma group can be determined by interactions of the pathogen, vector, and host(s), with differential susceptibility of a plant host species to each pathogen as well as vector feeding preferences, serving as primary determining factors. It has been demonstrated that Candidatus phytoplasma aurantifolia is transmitted by Hishimonus phycitis (Salehi et al., 2007). Therefore, presence of this phytoplasma in safflower is not of great phytosanitary significance due to its low incidence of symptomatic safflower $(<0.2 \%)$ per field. However, it could represent a potential threat for disease spread to other crops and landscape trees in Iran.

Safflower has never been reported to be a preferred natural host of this leafhoppers (Jeger et al., 2017) but some phytoplasma-transmitted leaf hoppers, including Neoaliturus fenestratus, Macrosteles laevis, Psammotettix striatus and Circulifer haematoceps, have been reported as pest on safflower in Iran (Saeidi et al., 2011) which can be potential vectors of this disease in Iran. It is recommended to conduct future research on insect transmission of peanut witches' broom phytoplasma group to safflower.

\section{Literature}

Deng, S. and Hiruki, C. (1991): Amplification of 16S rRNA genes from culturable and nonculturable Mollicutes. J. Microb. Methods 14, 53-61.

Doyle, J. J. and Doyle, J. L. (1987): A rapid DNA isolation procedure for small quantities of fresh leaf tissue. Phytochem Bulletin. 19, 11-15.

Gibb, K. S., Padovan, A. C. and Mogen, B. D. (1995): Studies on sweet potato little-leaf phytoplasmas detected in sweet potato and other species growing in Northern Australia. Phytopathology 85, 169-174.

Gundersen, D. E. and Lee, I. M. (1996): Ultrasensitive detection of phytoplasmas by nested-PCR assays using two universal primer pairs. Phytopathol. Medit 35, 144-151.

Hodgetts, J., Ball, T., Boonham, N., Mumford, R. and Dickinson, M. (2007): Taxonomic groupings based on the analysis on the $16 \mathrm{~s} / 23 \mathrm{~s}$ spacer regions which shows greater variation than the normally used $16 \mathrm{srRNA}$ gene results in classification similar to that derived from 16s rRNA data but with more detailed subdivisions. Plant Pathol. 56, 357-365.

Hogenhout, S. A., Oshima, K., Ammar, E.-D., Kakizawa, S., Kingdom, H. N. and Namba, S. (2008): Phytoplasmas: bacteria that manipulate plants and insects. Molecular Plant Pathol 9, 403-423.

Jeger, M., Bragard, C., Caffier, D., Candresse, T., Chatzivassiliou, E., Dehnen-Schmutz, K., Gilioli, G., Gregoire, J. C., Jaques Miret, J. A., Navajas Navarro, M., Niere, B., Parnell, S., Potting, R., Rafoss, T., Rossi, V., Urek, G., Van Bruggen, A., Van der Werf, W., West, J., Winter, S., Gardi, C., Aukhojee, M., Bergeretti, F. and MacLeod, A. (2017): Pest categorisation of Hishimonus phycitis. EFSA J. 15, 5037-5063.

Klein, M. (1970): Safflower phyllody, a mycoplasma disease of Carthamus tinctorius in Israel. Plant Dis. Rep. $54,735-738$.

Kumar, S., Stecher, G. and Tamura, K. (2016): MEGA7: Molecular Evolutionary Genetics Analysis version 7.0 for bigger datasets. Mol. Biol. Evol. 33, 1870-1874.

Lee, I. M., Davis, R. E. and Gundersen-Rindal, D. E. (2000): Phytoplasma: Phytopathogenic Mollicutes. Annual Rev. Microb. 54, 221-255.

Saeidi, K., Nur Azura, A., Omar, D. and Abood, F. (2011): Pests of safflower (Carthamus tinctorious L.) and their natural enemies in Gachsara, Iran. South Asian J. Exp. Biol. 1, 286-291. 
Salehi, M., Izadpanah, K., Siampour, M., Bagheri, A. and Faghihi, S. M. (2007): Transmission of 'Candidatus Phytoplasma aurantifolia' to Bakraee (Citrus reticulata hybrid) by feral Hishimonus phycitis leafhoppers in Iran. Plant Disease 91, 466.

Salehi, M., Izadpanah, K., Siampour, M., Firouz, R. and Salehi, E. (2009): Molecular characterization and transmission of safflower phylody phytoplasma in Iran. J. Plant Pathol. 91, 453-458.

Schneider, B., Seemüller, E., Smart, C. D. and Kirkpatrick, B. C. (1995): Phylogenetic classification of plant pathogenetic mycoplasma-like organisms or phytoplasmas. In: S. Razin and J. G. Tully (eds): Molecular and Diagnostic Procedures in Mycoplasmology. Academic Press, Vol. I, San Diego, CA, USA, pp. 369-380.

Tamura, K. and Nei, M. (1993): Estimation of the number of nucleotide substitutions in the control region of mitochondrial DNA in humans and chimpanzees. Mol. Biol. Evol. 10, 512-526.

Tamura, K., Nei, M. and Kumar, S. (2004): Prospects for inferring very large phylogenies by using the neighbor-joining method. Proc. of the National Academy of Sciences (USA) 101, 11030-11035.

Thompson, J. D., Gibson, T. J., Plewniak, F., Jeanmougin, F. and Higgins, D. G. (1997): The CLUSTAL X windows interface: flexible strategies for multiple sequence alignment aided by quality analysis tools. Nucleic Acids Resarch 25, 4876-4882.

Zohary, D., Hopf, M. and Weiss, E. (2012): Domestication of Plants in the Old World: The Origin and Spread of Domesticated Plants in Southwest Asia, Europe and the Mediterranean Basin. Oxford University Press, 4th ed. 168 p. ISBN 0199549060.

Zhao, Y., Wei, W., Lee, I. M., Shao, J., Suo, X. and Davis, R. E. (2009): Construction of an interactive online phytoplasma classification tool, iPhyClassifier, and its application in analysis of the peach X-disease phytoplasma group (16SrIII). International J. Systematic and Evolutionary Microbiol. 59, 2582-2593.

Zreik, L., Carle, P., Bove, J. M. and Garnier, M. (1995): Characterization of the mycoplasmalike organism associated with witches-broom disease of lime and proposition of a candidatus taxon for the organism, Candidatus-phytoplasma-aurantifolia. Int. J. Syst. Bacteriol. 45, 449-453.

Wei, W., Davis, R. E., Lee, M. and Zhao, Y. (2007): Computer-simulated RFLP analysis of 16SrRNA genes: identification of ten new phytoplasma groups. International J. Systematic and Evolutionary Microbiol. 57, 1855-1867.

Wei, W., Lee, I. M., Davis, R. E., Suo, X. and Zhao, Y. (2008): Automated RFLP pattern comparison and similarity coefficient calculation for rapid delineation of new and distinct phytoplasma 16Sr subgroup lineages. International J. Systematic and Evolutionary Microbiol. 58, 2368-2377.

Weintraub, P. G. and Beanland, L. (2006): Insect vectors of phytoplasmas. Annual Rev. Ent. 51, 91-111. 
